\title{
Earthquake source parameters and scaling relationships in Hungary (central Pannonian basin)
}

\author{
Bálint Süle · Zoltán Wéber
}

\begin{abstract}
Fifty earthquakes that occurred in Hungary (central part of the Pannonian basin) with local magnitude $M_{L}$ ranging from 0.8 to 4.5 have been analyzed. The digital seismograms used in this study were recorded by six permanent broad-band stations and twenty short-period ones at hypocentral distances between 10 and $327 \mathrm{~km}$. The displacement spectra for $\mathrm{P}$ - and $\mathrm{SH}$-waves were analyzed according to Brune's source model. Observed spectra were corrected for path-dependent attenuation effects using an independent regional estimate of the quality factor $Q_{S}$. To correct spectra for near-surface attenuation, the $\kappa$ parameter was calculated, obtaining it from waveforms recorded at short epicentral distances. The values of the $\kappa$ parameter vary between 0.01 to $0.06 \mathrm{~s}$ with a mean of $0.03 \mathrm{~s}$ for P-waves and between 0.01 to $0.09 \mathrm{~s}$ with a mean of $0.04 \mathrm{~s}$ for $\mathrm{SH}$-waves. After correction for attenuation effects, spectral parameters (corner frequency and low-frequency spectral level) were estimated by a grid search algorithm. The obtained seismic moments range from $4.21 \times 10^{11}$ to $3.41 \times 10^{15} \mathrm{Nm}\left(1.7 \leq M_{w} \leq 4.3\right)$. The source radii are between 125 and $1343 \mathrm{~m}$. Stress drop values vary between 0.14 and 32.4 bars with a logarithmic mean of 2.59 bars $\left(1 \mathrm{bar}=10^{5} \mathrm{~Pa}\right)$. From the results, a linear relationship between local and moment magnitudes has been established. The obtained scaling relations show slight evidence of self-similarity violation. However, due to the high scatter of our data, the existence of self-similarity cannot be excluded.
\end{abstract}

Keywords Spectral analysis - Source parameters - Moment magnitude $\cdot$ Scaling relations $\cdot \kappa$ parameter $\cdot$ Hungary

B. Süle $\cdot$ Z. Wéber

Kövesligethy Radó Seismological Observatory, MTA CSFK GGI, Meredek u.18., H-1112 Budapest, Hungary

E-mail: suba@seismology.hu (B. Süle); weber@seismology.hu (Z. Wéber)

\section{Introduction}

The Pannonian depression is a sedimentary back-arc basin in central Europe and is an integral part of the AlpineCarpathian orogenic mountain belts. Geophysical features such as an updoming of the mantle, a thinned lower crust, and a strong geothermal anomaly are all characteristic to the basin. The crust is rather thick in the mountain ranges around the Pannonian basin, whereas the basin itself is characterized by thin crust, ranging from 22.5 to $30 \mathrm{~km}$, where the $30 \mathrm{~km}$ depth isoline encircles the whole basin (Horváth, 1993). The lithosphere also has smaller thickness than the average. Several geophysical studies suggest that the lithosphere under the basin is thinner than $80 \mathrm{~km}$ (e.g. Babuska et al., 1987; Posgay et al., 1995).

The recent tectonic activity of the region is basically determined by the counterclockwise rotation of the Adriatic microplate relative to Europe. The present-day kinematics of the Pannonian basin shows that the area is pushed from the south-southwest. As a result, strike-slip to compressive faulting is observed well inside the Pannonian basin. The nearly complete absence of normal faulting in the area suggests that in the Pannonian basin structural inversion is in progress, causing an increase of the intraplate compressional stress (Bada et al., 1999; Gerner et al., 1999).

In the central part of the Pannonian basin (mainly occupied by Hungary), seismic activity can be characterized as moderate. The seismicity pattern in Hungary shows that earthquakes are restricted to the upper part of the crust and the control by pre-existing fault zones is strongly masked by the random hypocentral distribution due to the general weakness of the lithosphere. However, there are certain areas where the likelihood of earthquake occurrence is higher and where significant, destructive earthquakes occurred in the last centuries. The most notable events are the M6.2 Komárom $\left(1763, I_{\max }=8-9\right)$, the M5.4 Mór (1810, $\left.I_{\max }=8\right)$, the M5.6 Kecskemét $\left(1911, I_{\max }=8\right)$, the M5.3 
Eger (1925, $\left.I_{\max }=7-8\right)$, or the M5.6 Dunaharaszti (1956, $I_{\max }=8$ ) earthquake. The epicenter of the latter event was in the close vicinity of Budapest, the capital of Hungary. Statistical studies show that four to five 2.5-3.5 magnitude earthquakes can be expected every year in the country, which can be felt near the epicenter, but cause no damage. Earthquakes causing light damages occur every 15-20 years, whereas stronger, more damaging $(M=5.5-6)$ quakes happen about every 40-50 years.

Knowledge of the source mechanisms and source parameters of local earthquakes helps us to better understand recent tectonic processes in the Pannonian basin. One possible method for estimating earthquake source parameters is the spectral analysis of observed waveforms. Indeed, the resolution of source parameters, such as seismic moment $\left(M_{0}\right)$, corner frequency $\left(f_{c}\right)$ and source radius $(r)$, is of fundamental interest in the derivation of earthquake scaling relationships with decreasing magnitude and the determination of the stress drops $(\Delta \sigma)$ of local earthquakes. The scaling laws are important to define the relationships between earthquake size (seismic moment or magnitude), fault dimensions and stress drop for a specified seismic area. For example, when reliable estimates of the stress release are obtained over several orders of magnitude of seismic moment for a given area, the scaling laws can be used for seismic hazard predictions: records of small events can be used to predict the ground motion of moderate-to-large earthquakes in the same region (e.g. Kamae et al., 1998). Moreover, stress drop also plays a fundamental role in simulating strong ground motion using stochastic methods (e.g. Boore, 2003).

Spectral analysis for the estimation of earthquake source parameters has been widely used by many authors following Brune's (Brune, 1970) source model (e.g. Chouet et al., 1978; Fletcher, 1980; Zobin and Havskov, 1995; Allen et al., 2004; Oye et al., 2005; Franceschina et al., 2006; Tusa and Gresta, 2008). However, there were only a few investigations so far that studied spectral source parameters for Hungarian earthquakes. Badawy (2000) analyzed the earthquake sequence that occurred in 1996 in the Füzesgyarmat region, Hungary. The local magnitudes of these 7 events were between 2.1 and 3.2. Another study of Badawy et al. (2001) presents the source parameters of 12 felt earthquakes in the period between 1995 and 1997. Nine of these events had an epicenter within Hungary with local magnitudes ranging from 2.4 to 3.7. Recently, Süle (2010) studied the P-wave displacement spectra of 18 earthquakes that occurred in two seismically active regions in Hungary. The local magnitude of the selected events varies between 1.2 and 3.7. This magnitude range is notably wider than those studied by Badawy (2000) and Badawy et al. (2001) and the author also derived some scaling laws ( $M_{0}$ vs. $r$ and $M_{0}$ vs. $\left.\Delta \sigma\right)$ and established a linear relationship between local and moment magnitudes. Unfortunately, in spite of the above efforts, the number, areal distribution and magnitude range of the earthquakes investigated up to now are still not sufficient to draw reliable conclusions on scaling relationships and stress drops for the Hungarian part of the Pannonian basin.

The data set used in this study covers a relatively large range of magnitude $\left(0.8 \leq M_{L} \leq 4.5\right)$ and allows us to obtain an estimate of source parameters from waveforms of smallto-moderate events by applying different methodology with respect to those used in the studies previously mentioned. For this purpose, in this article we invert the spectra of Pand $\mathrm{SH}$-wave seismograms for corner frequency and lowfrequency spectral level using the standard Brune's model (Brune, 1970), after correction for path-dependent and nearsurface attenuation, applying a grid search algorithm to find the unknown model parameters. Then we compute seismic moment, source dimension, and static stress drop of the selected 50 events for determining scaling laws and establishing a linear relationship between local and moment magnitudes.

\section{Data}

The digital data used in this study were recorded by six permanent broad-band stations (Hungarian National Seismological Network - HNSN) and twenty short-period ones (Paks Microseismic Monitoring Network - PMMN) (Fig. 1). Most of the PMMN stations were operated for only a limited period of time and do not work nowadays. The broad-band stations are equipped with threecomponent Streckeisen STS-2 seismometers with natural period of $120 \mathrm{~s}$, whereas the short-period stations use threecomponent Lennartz LE-3D geophones with natural frequency of $1 \mathrm{~Hz}$. The data were recorded with various sampling rates between 62.5 and $125 \mathrm{~Hz}$. The instrumental response of the recording equipments is almost flat to ground velocity between the natural frequency of the seismometer used $(0.0083$ or $1 \mathrm{~Hz})$ and about $25-50 \mathrm{~Hz}$. The upper limit is imposed by the cut-off frequency of the anti-alias low-pass filter.

The stations are located on different geological formations: some of them are located on sand or loess, others on gneiss, andesite, dolomite, or granite. Therefore, site effects can significantly vary from station to station.

Our data set consists of 50 earthquakes with local Richter magnitude $M_{L}$ ranging from 0.8 to 4.5 and with epicenters from all over the territory of Hungary (Fig. 1, Table 1). The events were selected on the basis of good signalto-noise ratio and accurate hypocentral location (RMS error of location less than $2 \mathrm{~km}$ ). The hypocentral distances of the recording stations vary between 10 and $327 \mathrm{~km}$, whereas the focal depth falls in the range of 1 to $21 \mathrm{~km}$. The local mag- 


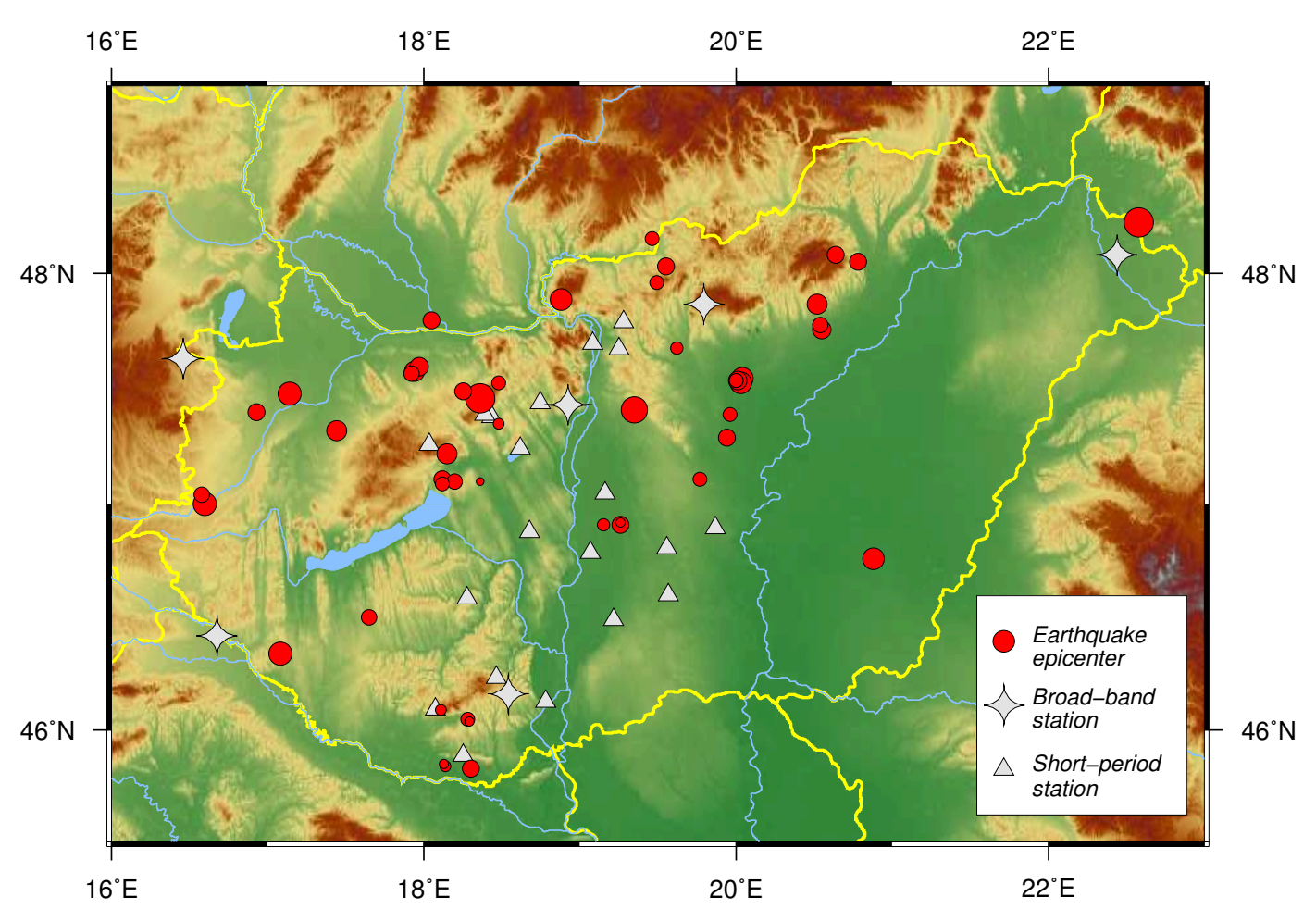

Fig. 1 Topographic map of Hungary showing the location of the seismic stations used in this study and the epicenters of the fifty earthquakes selected for spectral analysis. Symbol size is proportional to event magnitude.

nitudes were estimated according to the formula given by Bakun and Joyner (1984):

$M_{L}=\log (A)+1.00 \cdot \log (D)+0.00301 \cdot D-1.99$

where $D$ is the epicentral distance in kilometers and $A$ is the largest $\mathrm{S}$-wave amplitude measured in nanometers on a ground displacement seismogram that has been filtered with the response of a Wood-Anderson seismograph.

\section{Spectral analysis}

\subsection{Method}

For the source parameter analysis, we used the $P_{g}$ arrivals of the vertical component seismograms and the $S_{g}$ arrivals of the transverse component waveforms. First, the waveform to be analyzed was base-line corrected by removing the mean. Then a time window was selected for the desired ( $\mathrm{P}$ or $\mathrm{SH})$ phase, starting shortly before the arrival time. The time window was tapered with a Hann window at both ends of the time series. Signal windows of varying lengths were tested in order to select a length that would avoid contamination from other (mainly converted) phases and maintain the resolution and stability of the spectra. Then the velocity spectrum was calculated using the Fast Fourier Transform (FFT). The spectrum was subsequently corrected for instrumental response and converted to the displacement spectrum.
In order to obtain a spectral estimate of the noise, we analyzed a suitably chosen time window of the seismogram prior to the P-wave arrival. The length of this noise window was equal to that of the corresponding signal window. For source parameter estimation, we used the frequency band where the signal-to-noise spectral ratio was greater than 5 .

After instrumental correction, the observed displacement amplitude spectrum $U(f, R)$ at a hypocentral distance $R$ can be described as

$U(f, R)=G(R) \cdot A(f, t) \cdot S(f)$

where $f$ is the frequency, $t$ the travel time, $G(R)$ the attenuation due to geometrical spreading, $A(f, t)$ the anelastic attenuation, and $S(f)$ the amplitude source spectrum. In order to estimate the source spectrum $S(f)$, the observed spectrum $U(f, R)$ must be corrected for geometrical spreading and attenuation.

In this study, for calculating geometrical spreading, we use the formulation suggested by Havskov and Ottemöller (2010). For P-waves, $G(R)=1 / R$ is assumed. For S-waves, $G(R)$ depends on epicentral distance. For shorter distances $\left(R \leq R_{0}\right)$, S-waves can be treated as body waves and $G(R)=1 / R$ is again a reasonable assumption. For larger distances $\left(R>R_{0}\right)$, however, $\mathrm{S}$-waves are dominated by surface waves and geometrical spreading is approximated by $G(R)=1 / \sqrt{R R_{0}}$. The value of $R_{0}$ is regional dependent. In this work, we have chosen $R_{0}=100 \mathrm{~km}$. 
Table 1 Hypocentral parameters and local Richter magnitude $\left(M_{L}\right)$ of the earthquakes analyzed in this study. Data are collected from the Hungarian Earthquake Bulletins.

\begin{tabular}{|c|c|c|c|c|c|c|}
\hline $\begin{array}{l}\text { Event } \\
\text { No. }\end{array}$ & $\begin{array}{c}\text { Date } \\
\text { (yyyy-mm-dd) }\end{array}$ & $\begin{array}{c}\text { Time } \\
\text { (hh:mm) }\end{array}$ & $\begin{array}{l}\text { Longitude } \\
\left({ }^{\circ} \mathrm{E}\right)\end{array}$ & $\begin{array}{l}\text { Latitude } \\
\qquad\left({ }^{\circ} \mathrm{N}\right)\end{array}$ & $\begin{array}{r}\text { Depth } \\
(\mathrm{km})\end{array}$ & $M_{L}$ \\
\hline 1 & 1995-06-09 & $15: 57$ & 19.264 & 46.923 & 12.3 & 1.6 \\
\hline 2 & 1995-09-12 & $22: 14$ & 18.146 & 47.224 & 7.5 & 3.5 \\
\hline 3 & 1995-09-18 & $08: 26$ & 18.879 & 47.894 & 11.8 & 3.7 \\
\hline 4 & $1996-03-28$ & $06: 31$ & 19.256 & 46.910 & 13.9 & 3.0 \\
\hline 5 & $1997-05-23$ & $23: 40$ & 18.475 & 47.345 & 10.9 & 1.9 \\
\hline 6 & $1997-10-16$ & $12: 14$ & 18.356 & 47.103 & 10.0 & 0.8 \\
\hline 7 & 1999-06-04 & 02:09 & 18.302 & 45.826 & 3.0 & 3.0 \\
\hline 8 & $2000-02-16$ & $13: 22$ & 18.478 & 47.525 & 13.3 & 2.4 \\
\hline 9 & 2000-06-02 & $15: 17$ & 19.769 & 47.105 & 16.9 & 2.6 \\
\hline 10 & $2000-11-23$ & $02: 32$ & 19.153 & 46.908 & 10.0 & 2.1 \\
\hline 11 & 2001-03-29 & $22: 42$ & 18.048 & 47.802 & 8.8 & 2.9 \\
\hline 12 & $2001-05-25$ & $15: 15$ & 18.139 & 45.836 & 10.0 & 1.7 \\
\hline 13 & 2001-06-08 & 09:58 & 18.131 & 45.852 & 12.6 & 1.2 \\
\hline 14 & 2001-06-28 & 07:08 & 18.119 & 47.107 & 10.0 & 3.0 \\
\hline 15 & $2002-01-28$ & $03: 18$ & 19.493 & 47.956 & 1.0 & 2.4 \\
\hline 16 & $2002-02-22$ & $11: 52$ & 18.248 & 47.492 & 10.0 & 2.9 \\
\hline 17 & $2002-02-25$ & $23: 10$ & 19.622 & 47.681 & 10.0 & 2.2 \\
\hline 18 & 2002-10-12 & $18: 49$ & 20.010 & 47.543 & 14.6 & 3.3 \\
\hline 19 & $2002-10-23$ & $02: 52$ & 20.043 & 47.545 & 14.3 & 3.7 \\
\hline 20 & $2002-12-25$ & $21: 58$ & 20.002 & 47.540 & 12.1 & 2.6 \\
\hline 21 & 2003-06-21 & $20: 05$ & 20.032 & 47.531 & 12.9 & 3.7 \\
\hline 22 & 2003-06-27 & 01:19 & 20.001 & 47.536 & 15.8 & 2.4 \\
\hline 23 & 2003-07-01 & $11: 26$ & 20.520 & 47.871 & 7.7 & 3.4 \\
\hline 24 & 2003-07-01 & $11: 46$ & 20.554 & 47.755 & 10.0 & 3.3 \\
\hline 25 & $2003-07-10$ & $02: 40$ & 19.457 & 48.151 & 5.9 & 2.4 \\
\hline 26 & 2003-07-13 & 02:29 & 20.643 & 48.078 & 13.1 & 3.1 \\
\hline 27 & 2003-07-19 & 09:12 & 20.538 & 47.783 & 3.1 & 2.8 \\
\hline 28 & 2003-08-09 & 22:01 & 16.597 & 46.996 & 8.2 & 3.8 \\
\hline 29 & 2003-08-31 & $22: 57$ & 18.106 & 46.088 & 7.6 & 1.9 \\
\hline 30 & $2003-12-16$ & 07:06 & 17.075 & 46.341 & 20.7 & 3.8 \\
\hline 31 & $2003-12-31$ & $20: 43$ & 18.275 & 46.046 & 10.0 & 2.6 \\
\hline 32 & 2003-12-31 & $21: 36$ & 18.287 & 46.038 & 9.4 & 1.6 \\
\hline 33 & $2004-05-25$ & $07: 30$ & 17.141 & 47.479 & 8.3 & 3.8 \\
\hline 34 & 2004-06-19 & $10: 48$ & 19.956 & 47.391 & 10.0 & 2.5 \\
\hline 35 & 2004-07-20 & $22: 13$ & 18.115 & 47.091 & 10.0 & 2.5 \\
\hline 36 & 2004-08-17 & $18: 00$ & 17.942 & 47.578 & 6.1 & 3.4 \\
\hline 37 & 2004-08-18 & 09:01 & 17.974 & 47.596 & 10.0 & 3.2 \\
\hline 38 & $2004-10-14$ & 09:44 & 17.922 & 47.572 & 10.0 & 2.8 \\
\hline 39 & $2005-05-15$ & $13: 30$ & 17.444 & 47.323 & 9.8 & 3.5 \\
\hline 40 & $2006-11-23$ & $07: 15$ & 22.583 & 48.216 & 10.0 & 4.5 \\
\hline 41 & 2006-12-31 & $13: 39$ & 19.345 & 47.405 & 5.2 & 4.1 \\
\hline 42 & 2007-03-03 & $20: 35$ & 16.931 & 47.402 & 6.4 & 3.0 \\
\hline 43 & 2007-11-18 & $14: 22$ & 19.552 & 48.033 & 3.4 & 3.0 \\
\hline 44 & $2008-11-13$ & $07: 47$ & 20.881 & 46.757 & 16.1 & 3.7 \\
\hline 45 & $2009-11-25$ & $10: 07$ & 18.199 & 47.100 & 10.0 & 2.8 \\
\hline 46 & 2010-02-08 & $15: 26$ & 17.645 & 46.496 & 16.5 & 2.7 \\
\hline 47 & $2010-05-25$ & $06: 55$ & 19.943 & 47.286 & 14.9 & 3.1 \\
\hline 48 & 2010-08-19 & 01:29 & 20.782 & 48.053 & 10.0 & 3.0 \\
\hline 49 & $2010-08-26$ & $22: 29$ & 16.580 & 47.039 & 12.9 & 2.7 \\
\hline 50 & 2011-01-29 & $17: 41$ & 18.361 & 47.459 & 9.1 & 4.5 \\
\hline
\end{tabular}

Anelastic attenuation can be divided into two parts (Singh et al., 1982):

$A(f, t)=\exp \left(-\frac{\pi f t}{Q(f)}\right) \cdot \exp (-\pi f \kappa)$

where the first term describes the path-dependent attenuation, with $Q(f)$ being the frequency-dependent quality fac- tor. The second term is the near-surface attenuation characterized by the $\kappa$ parameter.

Kiszely (2000) calculated coda- $Q$ values, $Q_{c}$, for five frequencies $(3,6,10,16,24 \mathrm{~Hz})$ using the waveforms of 19 local earthquakes that occurred in Hungary. Assuming that $Q_{c}$ is a good approximation of $Q_{S}$, we estimated $Q_{S}(f)$ by 

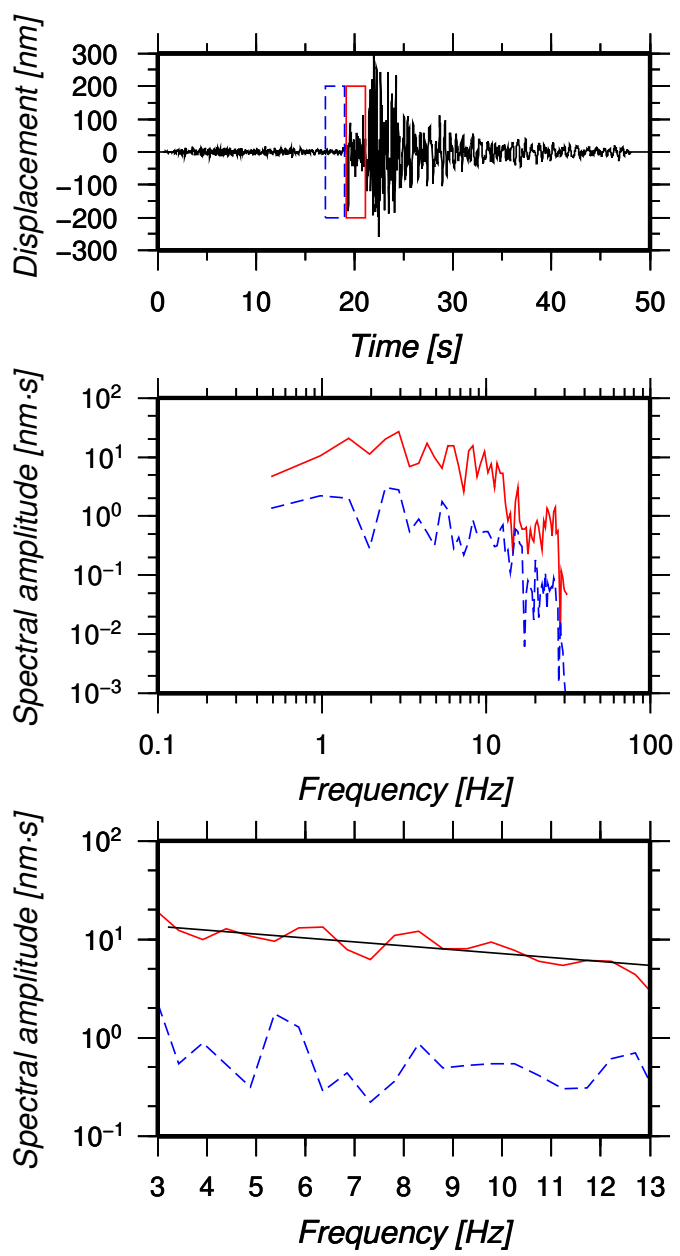

Fig. 2 Example for $\kappa$ estimation. Top: The analyzed seismogram with the selected signal and noise windows (red and blue rectangles, respectively). Middle: The ground displacement amplitude spectra of the signal (red) and noise (dashed blue). Bottom: The smoothed spectrum (red) below the corner frequency and its linear approximation (black). The slope of the line is proportional to $\kappa$.

fitting a theoretical curve on the five derived $f-Q_{c}$ points. Finally, we obtained the relation $Q_{S}(f)=77 f^{0.92}$. Unfortunately, there are no available $Q_{P}(f)$ values for the territory of Hungary. However, from several hundred earthquakes occurred within the San Andreas fault system, Abercrombie and Leary (1993) obtained $Q_{P} \approx 2 Q_{S}$ near the surface. Similar result was found by Anderson et al. (1965) in a study of $Q$ in the upper mantle where $Q_{P}=2.25 Q_{S}$. The same theoretical relation was published by Aki and Richards (1980) for an attenuating medium where all losses are confined to shear and none to pure compression. Adopting the above results, in this paper we assume the relation $Q_{P}(f)=154 f^{0.92}$ for the frequency-dependent $\mathrm{P}$-wave quality factor.

In the rest of this paper, we are going to estimate the near-surface attenuation using the method by Havskov and Ottemöller (2010) and then correct the observed displacement spectrum for geometrical spreading and anelastic at- tenuation (Eq. 3). Subsequently, using the standard Brune's source model (Brune, 1970), the resulting spectrum will be fitted by a theoretical curve with two unknown parameters: the low-frequency spectral level $A_{0}$ and the corner frequency $f_{c}$.

\subsection{Near-surface attenuation}

Before any further processing, the displacement spectra must be corrected for geometrical spreading and attenuation as described above. The attenuation has two effects: it changes the shape of the spectrum which affects the determination of the corner frequency and it also changes the low-frequency spectral level which affects the seismic moment estimation. Correcting for attenuation is particularly important for small earthquakes due to their significant highfrequency content.

Near-surface attenuation can be estimated from seismic waveforms recorded at short hypocentral distances, where the path-dependent attenuation in Eq. 3 is not significant (Havskov et al., 2003; Havskov and Ottemöller, 2010). For frequencies below the corner frequency, $\kappa$ can be determined from the slope of the displacement spectrum plotted in a semi-logarithmic diagram, as illustrated in Fig. 2.

For estimating near-surface effects, we selected all the available event-station pairs from our data set for which epicentral distance is less than $25 \mathrm{~km}$ and the event size is small enough to have a corner frequency as high as possible. This latter criteria is necessary for performing reliable line fitting in the usable frequency range. After analyzing 33 seismograms of eight stations, we obtained $\kappa$ values between 0.01 and $0.06 \mathrm{~s}$ with a mean of $0.03 \pm 0.017 \mathrm{~s}$ for P-waves and between 0.01 and $0.09 \mathrm{~s}$ with a mean of $0.04 \pm 0.024 \mathrm{~s}$ for $\mathrm{S}$-waves. Within the bounds of variation, the $\kappa$-value does not show a statistically significant scatter from one station to another. For this reason, we decided to apply the mean values for each station throughout the subsequent calculations.

In Fig. 3, we illustrate the effect of attenuation correction on three ground displacement spectra together with the theoretical Brune's model. Because the exponent of the frequency $f$ in $Q(f)$ used in this study is close to unity (0.92), the path-dependent attenuation (first term in Eq. 3) depends only slightly on frequency. In our case, therefore, the $Q$ correction practically does not change the shape of the spectra, that is it affects only the low-frequency spectral level and has negligible effect on the corner frequency $f_{c}$. On the other hand, near-surface attenuation (second term in Eq. 3) can seriously affect the shape of the spectra: for small earthquakes with significant high-frequency content, the near-surface attenuation dominates the high-frequency spectral decay and the real corner frequency cannot be seen. Therefore, for 


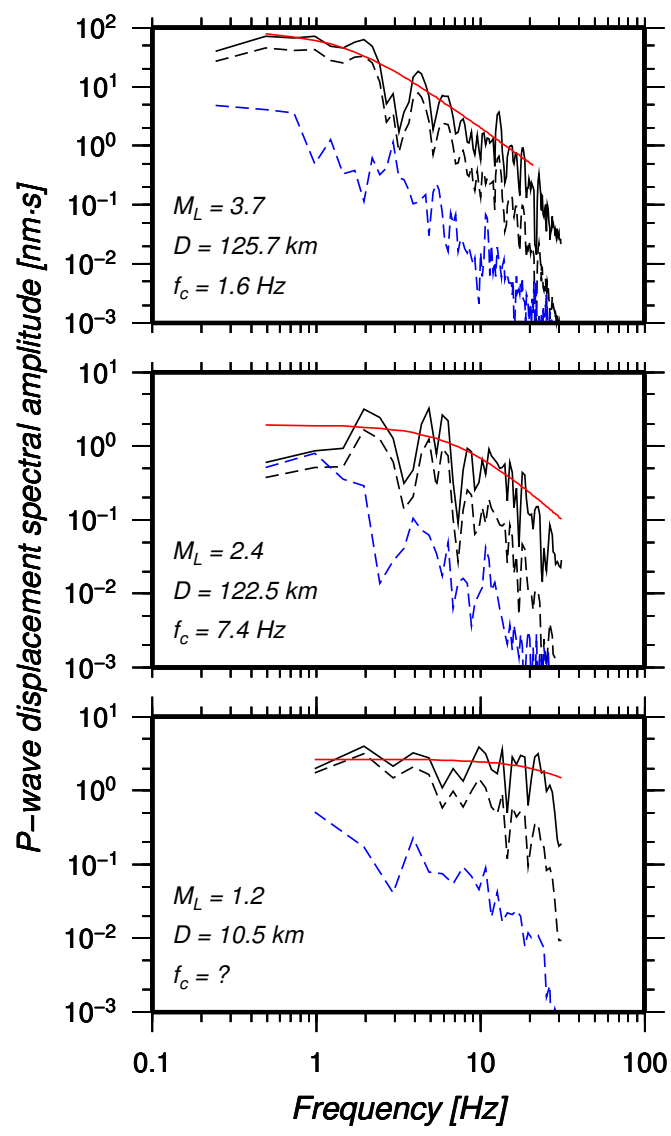

Fig. 3 Observed P-wave displacement spectra before (dashed black lines) and after (solid black lines) correction for attenuation effects, together with the theoretical Brune's spectra (red). The noise spectral amplitudes are also indicated (dashed blue). The illustrated spectra were calculated for events $19\left(M_{L}=3.7\right), 22\left(M_{L}=2.4\right)$, and $13\left(M_{L}=1.2\right)$. The values of local magnitude $\left(M_{L}\right)$, epicentral distance $(D)$ and corner frequency $\left(f_{c}\right)$ are also given.

small earthquakes, it is not possible to obtain the true corner frequency without correction for near-surface attenuation.

As can be seen in Fig. 3, the effect of attenuation correction on the displacement amplitude spectrum of an $M_{L}=3.7$ event (event 19 in Table 1) is quite moderate. However, for a smaller event (event 22, $M_{L}=2.4$ ), the attenuation correction has changed the shape of the spectrum notably causing an increase in the corner frequency. For an even smaller earthquake (event 13, $M_{L}=1.2$ ), the attenuation correction has flattened the spectrum making the estimation of the corner frequency impossible at the given sampling rate.
3.3 Spectral parameters

After correcting for geometrical spreading and anelastic attenuation, the displacement amplitude spectrum $U_{c}(f)$ can be written as

$U_{c}(f)=\frac{A_{0}}{1+\left(\frac{f}{f_{c}}\right)^{2}}$

where the term on the right-hand side is the amplitude source spectrum with low-frequency spectral level $A_{0}$ and corner frequency $f_{c}$ (Brune, 1970; Hanks and Wyss, 1972).

In Eq. 4, there are two unknown parameters to be determined: the low-frequency spectral level $A_{0}$ and the corner frequency $f_{c}$. In order to avoid problems associated with the visual determination of these parameters and to minimize the difference between the theoretical and observed displacement spectra, we applied a grid search algorithm. The misfit function to be minimized by the inversion procedure was the $L_{1}$ norm of the difference between the observed and predicted spectral values within a suitably chosen frequency range, where the signal-to-noise spectral ratio was greater than 5 . We chose the $L_{1}$ norm minimization technique because it is much more robust than the least-squares method. The global minimum of the misfit function defines the optimum solution for the unknown parameters. As an example, Fig. 4 shows the results of the above described inversion procedure for nine selected ground displacement spectra that are considered characteristic of our data set.

\section{Source parameters}

Considering P- and S-wave data separately, after estimating the spectral parameters we first calculated the scalar seismic moment $\left[M_{0}(P)\right.$ and $\left.M_{0}(S)\right]$ for each event-station pair according to Brune's source model (Brune, 1970; Hanks and Wyss, 1972):

$M_{0}=\frac{4 \pi \rho v^{3}}{F \Re(\theta, \varphi)} \cdot A_{0}$

where $\rho$ is the density, $v$ the velocity of the considered phase ( $\mathrm{P}$ or $\mathrm{S}), A_{0}$ the low-frequency spectral level, $F$ the free surface correction, and $\mathfrak{R}(\theta, \varphi)$ the radiation pattern coefficient. Since for most of the analyzed earthquakes the focal mechanism could not be determined, we used the RMS average values $\mathfrak{R}_{P}(\theta, \varphi)=0.52$ and $\mathfrak{R}_{S}(\theta, \varphi)=0.63$ in our calculations (Boore and Boatwright, 1984). The free surface correction for P-waves depends on the incident angle. However, due to the low-velocity layers near the surface, the incidence is not far from vertical, so $F=2$ seems to be a good approximation. For SH-waves, $F$ is always 2.

Then, for each event, the average values and the multiplicative error factors for the seismic moment and corner frequency were computed. Calculations were made using 

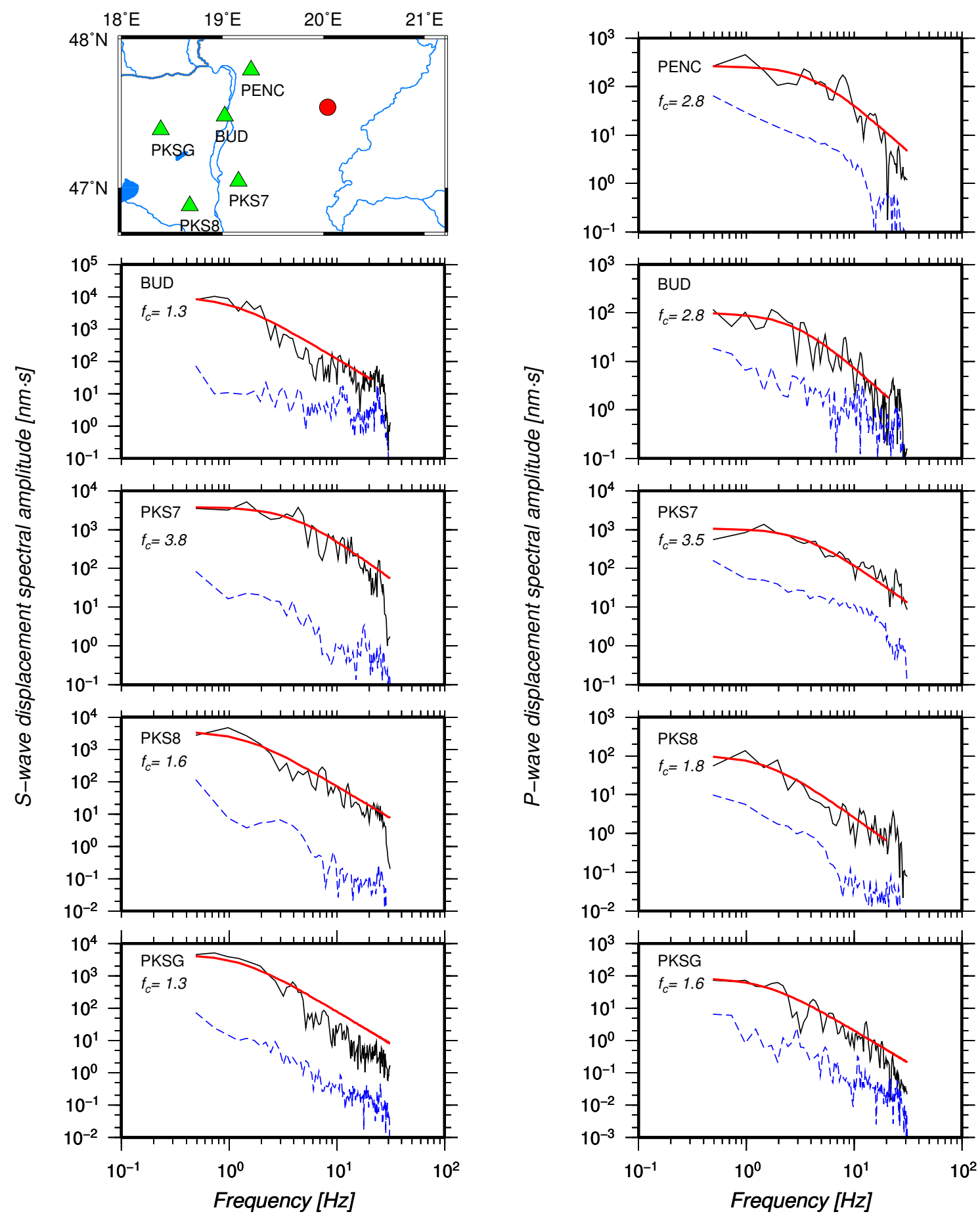

Fig. 4 Data acquisition geometry and corrected displacement amplitude spectra for event 19 (Table 1). The map shows the epicenter of the event (red solid circle) and the recording seismic stations (green triangles) with their codes. Each spectral diagram depicts the corrected amplitude spectrum of the selected signal (black) recorded at the indicated station, together with the best-fitting theoretical Brune's source model (red). The obtained corner frequency $f_{c}$ is given for each Brune's spectrum. Noise spectra are also illustrated (dashed blue). 


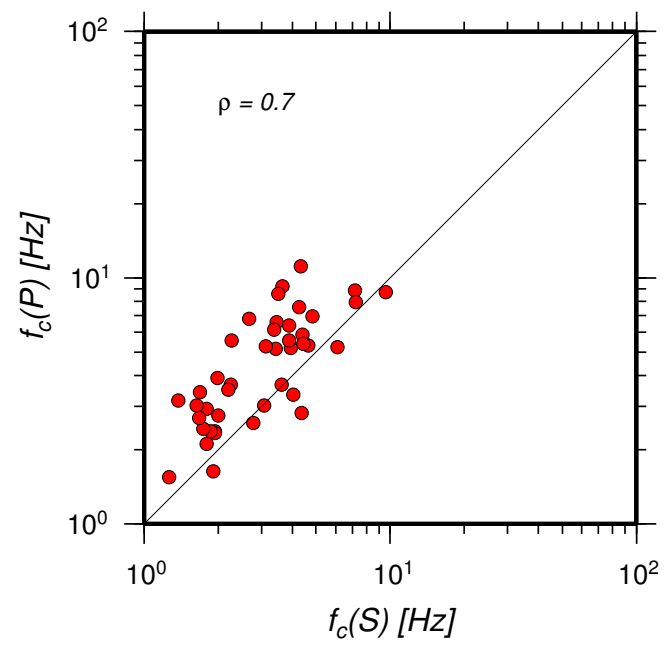

Fig. 5 P-wave corner frequency $f_{c}(P)$ versus S-wave corner frequency $f_{c}(S)$. The straight line represents the line for $f_{c}(P)=f_{c}(S)$. $\rho$ denotes the correlation coefficient.

P- and S-wave data separately, following the equations proposed by Archuleta et al. (1982):

$\bar{x}=\operatorname{alog}\left(\frac{1}{N} \sum_{i=1}^{N} \log x_{i}\right)$

$\operatorname{StDev}[\log \bar{x}]=\left(\frac{1}{N-1} \sum_{i=1}^{N}\left(\log x_{i}-\log \bar{x}\right)^{2}\right)^{1 / 2}$

$E \bar{x}=\operatorname{alog}(\operatorname{StDev}[\log \bar{x}])$

where $x$ stands for $M_{0}(P, S)$ or $f_{c}(P, S), \bar{x}$ denotes the mean of $x, N$ is the number of the stations used, StDev[.] is the standard deviation of the argument, and $E \bar{x}$ is the multiplicative error factor for $\bar{x}$.

Finally, we calculated the average source radius $\bar{r}$ and average stress drop $\overline{\Delta \sigma}$ using the expressions (Brune, 1970; Trifunac, 1972; Spottiswoode and McGarr, 1975):

$\bar{r}=\frac{C}{2 \pi} \frac{v}{\overline{f_{c}}}$

$\overline{\Delta \sigma}=\frac{7}{16} \frac{\overline{M_{0}}}{\bar{r}^{3}}$

where the constant $C$ is 1.97 for P-waves and 2.34 for $\mathrm{S}$ waves. We also computed the moment magnitude $M_{w}$ from the average seismic moment $M_{0}$ [computed as the logarithmic mean of the $M_{0}(P)$ and $M_{0}(S)$ values] according to the definition of Hanks and Kanamori (1979):

$M_{w}=\frac{2}{3} \log \overline{M_{0}}-6.03$

where $\overline{M_{0}}$ is measured in Nm. All of the average source parameters and the multiplicative error factors, along with the moment magnitudes, are listed in Table 2.

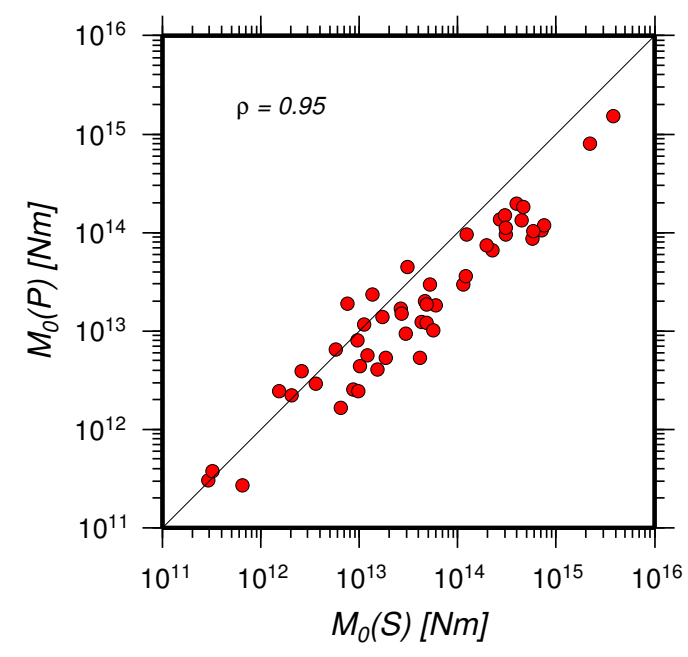

Fig. 6 P-wave seismic moment $M_{0}(P)$ versus $\mathrm{S}$-wave seismic moment $M_{0}(S)$. The straight line represents the line for $M_{0}(P)=M_{0}(S) . \rho$ denotes the correlation coefficient.

Our results show that the corner frequency generally decreases with increasing seismic moment. As can be seen in Fig. 5, the $f_{c}(P)$ and $f_{c}(S)$ values are in the range 1.6$11.2 \mathrm{~Hz}$ and $0.9-9.6 \mathrm{~Hz}$, respectively, and $f_{c}(P)$ is basically larger than $f_{c}(S)$, with an average ratio of $1.48 \pm 0.55$ (correlation coefficient of 0.7). Similar $f_{c}(P) / f_{c}(S)$ ratio was obtained by other authors (Fletcher, 1980; Boatwright et al., 1991; Radulian and Popa, 1996; García-García et al., 2004; Prieto et al., 2004; Tusa and Gresta, 2008, and others). The average multiplicative error factor is 1.5 for both $f_{c}(P)$ and $f_{c}(S)$. For seven low-magnitude events, the estimation of $f_{c}$ was unsuccessful due to the high corner frequency and the insufficient sampling rate.

The obtained seismic moments vary from $2.71 \times 10^{11}$ to $1.52 \times 10^{15} \mathrm{Nm}$ for P-waves, and from $2.90 \times 10^{11}$ to $3.83 \times 10^{15} \mathrm{Nm}$ for S-waves. Fig. 6 presents the relationship between $M_{0}(P)$ and $M_{0}(S)$. The logarithmic mean of the $M_{0}(P) / M_{0}(S)$ ratio is $0.93 \pm 0.07$ with a correlation coefficient of 0.95 . Generally, $M_{0}(S)$ is slightly larger than $M_{0}(P)$ that may be attributed to a somewhat overestimated $Q_{P}$ quality factor.

The source radii are between 125 and $1343 \mathrm{~m}$ with an average $r(P) / r(S)$ ratio of $1.04 \pm 0.40$ with a correlation coefficient of 0.8 (Fig. 7). The agreement between source radii from $\mathrm{P}$ - and $\mathrm{S}$-waves provides enough confidence that Eq. 9, and particularly the constant $C$ in that equation, for evaluating the source dimension was correctly applied (Spottiswoode and McGarr, 1975).

The static stress drop spans from 0.14 to 32.4 bars with a logarithmic mean of 2.59 bars $\left(1\right.$ bar $\left.=10^{5} \mathrm{~Pa}\right)$. Indeed, about 80 per cent of the computed stress drop values are less than 10 bars, significantly smaller than the value of 100 bars suggested by Kanamori and Anderson (1975) for intraplate 


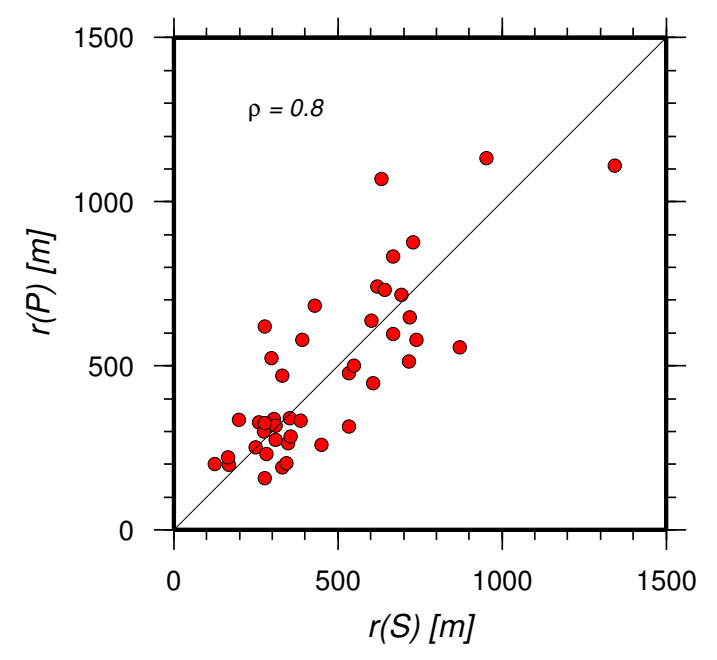

Fig. $7 \mathrm{P}$-wave source radius $r(P)$ versus $\mathrm{S}$-wave source radius $r(S)$. The straight line represents the line for $r(P)=r(S)$. $\rho$ denotes the correlation coefficient.

earthquakes. This observation may be attributed to the general weakness of the lithosphere due to the updoming of the mantle and the strong geothermal anomaly characteristic to the inner part of the Pannonian basin.

\section{Scaling relationships}

The generally accepted theory of self-similarity predicts a constant stress drop $\Delta \sigma$ for earthquakes of different size in the same tectonic environment. If the stress drop is constant, from Eq. 10 it follows that $r \propto M_{0}^{1 / 3}$. Indeed, a good number of papers have reported self-similarity for small seismic events in different regions (e.g. Abercrombie, 1995; Bindi et al,, 2001; Stork and Ito, 2004; Franceschina et al., 2006; Tusa et al., 2006; Yamada et al., 2007; Kwiatek et al., 2011). However, several authors have observed that for weak events, stress drop decreases with decreasing moment indicating a breakdown in constant stress drop scaling (e.g. Dysart et al., 1988; Zobin and Havskov, 1995; GarcíaGarcía et al., 2004; Tusa and Gresta, 2008; Drouet et al., 2010).

Regarding our data set, the relation between $M_{0}$ and static stress drop $\Delta \sigma$ is shown in Fig. 8 for both P- and Swaves. The highly scattered data points show only very little correlation. Indeed, the correlation coefficients between $M_{0}$ and $\Delta \sigma$ are very low: only 0.37 for P-waves and 0.5 for $\mathrm{S}$ waves. However, a slight trend of decreasing stress drop with decreasing seismic moment is visible for both wave types, particularly for S-waves.

In Fig. 9, source radius $r$ is plotted against $M_{0}$ and lines of constant stress drop are also indicated. The observed trend is a general increase of the fault radius with increasing seismic moment. The relations obtained for $r$ versus $M_{0}$ are

$\log r(P)=(0.24 \pm 0.03) \cdot \log M_{0}(P)-(0.64 \pm 0.48)$

and

$\log r(S)=(0.21 \pm 0.03) \cdot \log M_{0}(S)-(0.34 \pm 0.43)$

with correlation coefficients of 0.73 and 0.72 , respectively. The slope of the regression line is clearly smaller than the theoretical value of $1 / 3$. As a consequence, a breakdown in self-similarity appears to be present over the magnitude range considered in this study.

Figs. 8 and 9, and also Eqs. 12 and 13 suggest that our data is close to the limit where self-similarity violation begins. However, due to the high scatter of our data, constant stress drop scaling with $\Delta \sigma=2.59$ bars cannot be unanimously excluded. The estimated stress drop values are mostly confined in the range of $0.1-10$ bars. It should also be noted that the strongest events of our data set do not show particularly high stress drops. For events 40, 41, and 50 with local magnitudes above $4, \Delta \sigma(P)[\Delta \sigma(S)]$ is 6.07 [32.4], 2.33 [6.32], and 4.58 [19.3] bars, respectively (Table 2).

According to the definition of Hanks and Kanamori (1979), moment magnitude $M_{w}$ can be derived from seismic moment $M_{0}$ (Eq. 11). The moment magnitude scale does not saturate and recently it has become increasingly important in seismic hazard calculations. For example, ground-motion prediction equations for peak ground acceleration and velocity are usually expressed as functions of $M_{w}$ (e.g. Atkinson and Boore, 2006; Akkar and Bommer, 2007; Sokolov et al., 2008). For this reason, it is usual to find empirical formulae relating $M_{w}$ to the magnitude scales used locally in seismological practice. Fig. 10 shows the relationship between the moment magnitudes determined in this study (Table 2) and the local magnitude scale used in Hungary. The leastsquares fit to the data yields

$M_{w}=(0.71 \pm 0.03) \cdot M_{L}+(0.97 \pm 0.09)$

with a rather high correlation coefficient of 0.96 and with a slope that is very close to the expected theoretical value of 2/3 (Havskov and Ottemöller, 2010). The obtained regression line is in good agreement with that suggested by Süle (2010).

\section{Conclusions}

In this study, we determined the spectral source parameters of 50 local earthquakes that occurred in Hungary with local magnitude ranging from 0.8 to 4.5 . The scaling relations between these parameters were also investigated.

In order to correct for near-surface attenuation, we estimated the $\kappa$ parameter from seismic waveforms recorded 

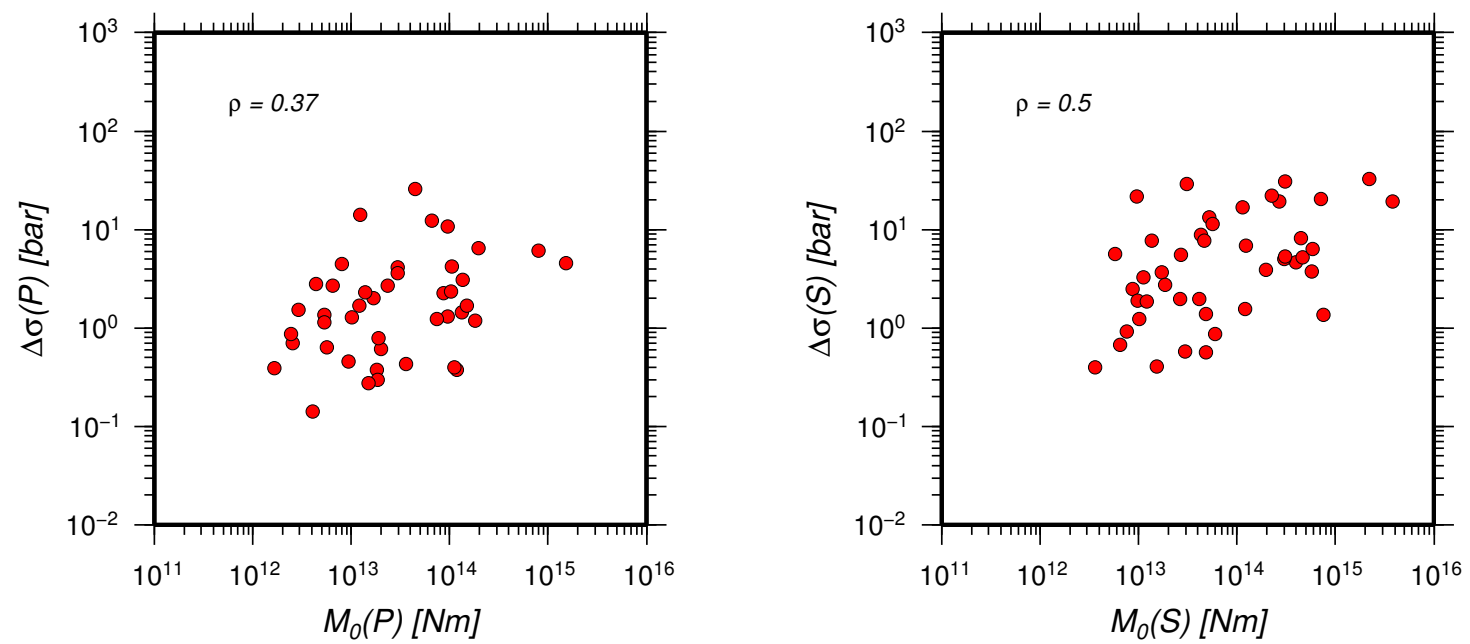

Fig. 8 Stress drop $\Delta \sigma$ versus seismic moment $M_{0}$ for both P-and S-waves. $\rho$ denotes the correlation coefficient.
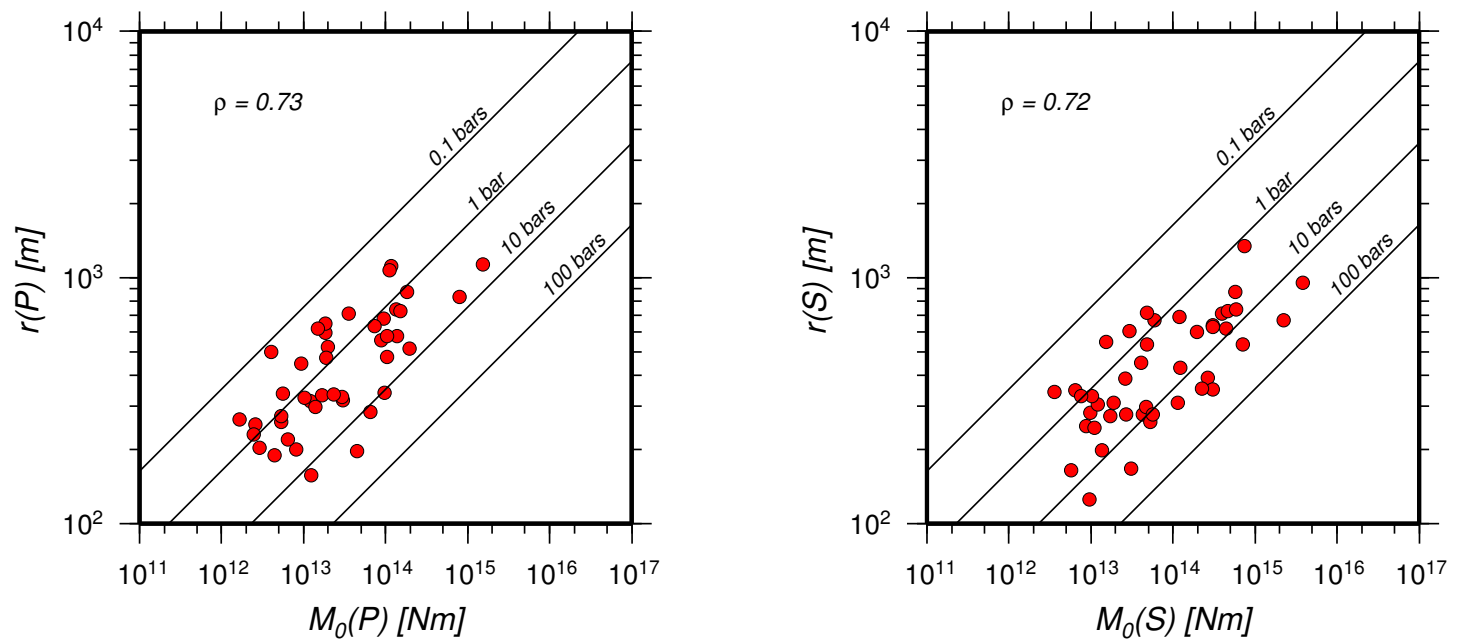

Fig. 9 Plot of source radius $r$ versus seismic moment $M_{0}$ for both P- and S-waves. Lines of constant stress drop are also shown. $\rho$ denotes the correlation coefficient.

at short hypocentral distances using the slope of the displacement spectrum below the corner frequency. The obtained $\kappa$ values vary between 0.01 and $0.06 \mathrm{~s}$ with a mean of $0.03 \pm 0.017 \mathrm{~s}$ for $\mathrm{P}$-waves and between 0.01 and $0.09 \mathrm{~s}$ with a mean of $0.04 \pm 0.024 \mathrm{~s}$ for $\mathrm{S}$-waves. Within the bounds of variation, the $\kappa$-value does not show any statistically significant dependence on station location.

After correcting the displacement amplitude spectra for attenuation effects, the obtained source spectra show a good agreement with Brune's model, thus allowing reliable estimation of the spectral parameters. We applied a grid search algorithm to find out the optimum values of the lowfrequency spectral level $A_{0}$ and the corner frequency $f_{c}$. The determined corner frequencies range from 0.9 to $11.7 \mathrm{~Hz}$ with an average $f_{c}(P) / f_{c}(S)$ ratio of 1.48 .

Using Brune's source model and the obtained spectral parameters, we calculated the source parameters of the in- vestigated earthquakes. The resulting values of seismic moment $M_{0}$ and source radius $r$ are limited to the ranges $2.71 \times 10^{11}$ to $3.83 \times 10^{15} \mathrm{Nm}$ and 125 to $1343 \mathrm{~m}$, respectively. The average $M_{0}(P)$ to $M_{0}(S)$ ratio is 0.93 , whereas the source sizes estimated from $\mathrm{P}$-waves are in good agreement with those estimated from S-waves.

The values of stress drop $\Delta \sigma$ vary between 0.14 and 32.4 bars with an average of 2.59 bars. The obtained scaling relations show slight evidence of self-similarity violation over the magnitude range considered in this study. It should be noted, however, that due to the high scatter of our data, the existence of self-similarity cannot be excluded. The fairly low average value of the stress drop may be attributed to the general weakness of the lithosphere beneath the central part of the Pannonian basin. 
Table 2 Moment magnitude $\left(M_{w}\right)$, scalar moment $\left(M_{0}\right)$, corner frequency $\left(f_{c}\right)$, source radius $(r)$, and stress drop $(\Delta \sigma)$ of the studied earthquakes with the multiplicative error factor for $M_{0}\left(E M_{0}\right)$ and $f_{c}\left(E f_{c}\right)$. Results are given for P- and S-wave data separately. $\left(\mathrm{Unit}\right.$ of stress: 1 bar $=10^{5} \mathrm{~Pa}$. $)$

\begin{tabular}{|c|c|c|c|c|c|c|c|c|c|c|c|c|c|}
\hline $\begin{array}{c}\text { Event } \\
\text { No. }\end{array}$ & $M_{w}$ & $\begin{array}{c}M_{0}(P) \\
(\mathrm{Nm})\end{array}$ & $E M_{0}(P)$ & $\begin{array}{c}M_{0}(S) \\
(\mathrm{Nm})\end{array}$ & $E M_{0}(S)$ & $\begin{array}{r}f_{c}(P) \\
(\mathrm{Hz})\end{array}$ & $E f_{c}(P)$ & $\begin{array}{r}f_{c}(S) \\
(\mathrm{Hz})\end{array}$ & $E f_{c}(S)$ & $\begin{array}{c}r(P) \\
(\mathrm{m})\end{array}$ & $\begin{array}{l}r(S) \\
(\mathrm{m})\end{array}$ & $\begin{array}{r}\Delta \sigma(P) \\
\quad(\text { bar })\end{array}$ & $\begin{array}{r}\Delta \sigma(S) \\
\quad(\text { bar })\end{array}$ \\
\hline 1 & 2.4 & $3.90 \mathrm{E}+12$ & 2.20 & $2.59 \mathrm{E}+12$ & 2.06 & - & - & - & - & - & - & - & - \\
\hline 2 & 3.6 & $1.37 \mathrm{E}+14$ & 2.50 & $2.66 \mathrm{E}+14$ & 2.77 & 3.0 & 1.17 & 3.1 & 1.22 & 580 & 392 & 3.08 & 19.20 \\
\hline 3 & 3.7 & $1.05 \mathrm{E}+14$ & 1.94 & $7.10 \mathrm{E}+14$ & 3.39 & 3.7 & 1.31 & 2.3 & 1.25 & 477 & 534 & 4.22 & 20.50 \\
\hline 4 & 3.1 & $4.48 \mathrm{E}+13$ & 1.94 & $3.08 \mathrm{E}+13$ & 2.65 & 8.9 & 1.41 & 7.2 & 1.47 & 197 & 167 & 25.60 & 28.90 \\
\hline 5 & 2.3 & $2.24 \mathrm{E}+12$ & 2.72 & $2.04 \mathrm{E}+12$ & 2.77 & - & - & - & - & - & - & - & - \\
\hline 6 & 1.7 & $3.06 \mathrm{E}+11$ & 1.14 & $2.90 \mathrm{E}+11$ & 1.73 & - & - & - & - & - & - & - & - \\
\hline 7 & 3.0 & $1.23 \mathrm{E}+13$ & 2.01 & $4.33 E+13$ & 3.13 & 11.2 & 1.08 & 4.3 & 1.28 & 157 & 277 & 14.00 & 8.91 \\
\hline 8 & 2.5 & $2.56 \mathrm{E}+12$ & 2.81 & $8.70 \mathrm{E}+12$ & 2.99 & 7.0 & 1.49 & 4.8 & 1.66 & 252 & 249 & 0.70 & 2.47 \\
\hline 9 & 2.7 & $8.05 \mathrm{E}+12$ & 1.60 & $9.65 \mathrm{E}+12$ & 1.80 & 8.8 & 1.63 & 9.6 & 1.38 & 200 & 125 & 4.43 & 21.50 \\
\hline 10 & 2.5 & $2.46 \mathrm{E}+12$ & 1.41 & $9.80 \mathrm{E}+12$ & 1.41 & 7.6 & 1.02 & 4.3 & 1.71 & 231 & 283 & 0.88 & 1.89 \\
\hline 11 & 2.9 & $5.30 \mathrm{E}+12$ & 3.42 & $4.13 \mathrm{E}+13$ & 2.42 & 6.8 & 1.79 & 2.7 & 1.66 & 258 & 450 & 1.36 & 1.98 \\
\hline 12 & 1.8 & $3.74 \mathrm{E}+11$ & 1.29 & $3.20 \mathrm{E}+11$ & 1.87 & - & - & - & - & - & - & - & - \\
\hline 13 & 1.8 & $2.71 \mathrm{E}+11$ & 1.62 & $6.55 \mathrm{E}+11$ & 1.71 & - & - & - & - & - & - & - & - \\
\hline 14 & 3.1 & $2.00 \mathrm{E}+13$ & 1.94 & $4.66 \mathrm{E}+13$ & 2.25 & 3.4 & 1.82 & 4.0 & 1.87 & 522 & 297 & 0.61 & 7.77 \\
\hline 15 & 2.7 & $5.65 \mathrm{E}+12$ & 2.00 & $1.21 \mathrm{E}+13$ & 1.46 & 5.2 & 1.75 & 3.9 & 1.63 & 338 & 305 & 0.64 & 1.85 \\
\hline 16 & 3.0 & $1.21 \mathrm{E}+13$ & 1.87 & $4.83 \mathrm{E}+13$ & 2.64 & 5.6 & 1.32 & 2.3 & 1.60 & 314 & 533 & 1.70 & 1.39 \\
\hline 17 & 2.4 & $1.67 \mathrm{E}+12$ & 1.16 & $6.50 \mathrm{E}+12$ & 1.32 & 6.6 & 2.51 & 3.5 & 1.89 & 265 & 348 & 0.39 & 0.68 \\
\hline 18 & 3.3 & $2.98 \mathrm{E}+13$ & 2.02 & $1.15 \mathrm{E}+14$ & 1.91 & 5.5 & 1.57 & 3.9 & 1.78 & 317 & 310 & 4.10 & 16.80 \\
\hline 19 & 3.7 & $1.34 \mathrm{E}+14$ & 2.22 & $4.43 \mathrm{E}+14$ & 1.36 & 2.4 & 1.30 & 1.9 & 1.81 & 741 & 620 & 1.44 & 8.14 \\
\hline 20 & 2.7 & $4.03 \mathrm{E}+12$ & 2.36 & $1.54 \mathrm{E}+13$ & 1.54 & 3.5 & 2.40 & 2.2 & 1.41 & 500 & 549 & 0.14 & 0.41 \\
\hline 21 & 3.6 & $9.60 \mathrm{E}+13$ & 2.44 & $3.07 \mathrm{E}+14$ & 1.36 & 5.2 & 1.25 & 3.4 & 1.95 & 340 & 352 & 10.70 & 30.90 \\
\hline 22 & 2.6 & $4.38 \mathrm{E}+12$ & 2.40 & $1.02 \mathrm{E}+13$ & 1.32 & 9.2 & 1.19 & 3.6 & 1.87 & 190 & 330 & 2.78 & 1.24 \\
\hline 23 & 3.7 & $1.98 \mathrm{E}+14$ & 2.97 & $3.94 \mathrm{E}+14$ & 2.28 & 3.4 & 1.51 & 1.7 & 1.66 & 513 & 716 & 6.41 & 4.69 \\
\hline 24 & 3.5 & $6.55 \mathrm{E}+13$ & 2.65 & $2.24 \mathrm{E}+14$ & 2.54 & 6.2 & 1.81 & 3.4 & 1.34 & 285 & 355 & 12.40 & 21.90 \\
\hline 25 & 3.0 & $1.68 \mathrm{E}+13$ & 2.05 & $2.63 E+13$ & 2.13 & 5.3 & 1.64 & 3.1 & 1.73 & 333 & 387 & 1.99 & 1.98 \\
\hline 26 & 3.4 & $9.50 \mathrm{E}+13$ & 1.57 & $1.24 \mathrm{E}+14$ & 2.10 & 2.6 & 1.19 & 2.8 & 1.27 & 682 & 430 & 1.31 & 6.82 \\
\hline 27 & 3.1 & $2.94 \mathrm{E}+13$ & 3.10 & $5.25 \mathrm{E}+13$ & 1.89 & 5.3 & 1.92 & 4.6 & 1.24 & 328 & 259 & 3.63 & 13.20 \\
\hline 28 & 3.6 & $8.75 E+13$ & 2.06 & $5.70 \mathrm{E}+14$ & 2.01 & 3.2 & 1.52 & 1.4 & 1.27 & 555 & 871 & 2.24 & 3.78 \\
\hline 29 & 2.4 & $2.93 \mathrm{E}+12$ & 2.32 & $3.62 \mathrm{E}+12$ & 3.75 & 8.6 & 1.29 & 3.5 & 1.82 & 204 & 342 & 1.52 & 0.40 \\
\hline 30 & 3.7 & $1.83 \mathrm{E}+14$ & 1.73 & $4.60 \mathrm{E}+14$ & 2.82 & 2.3 & 1.34 & 1.9 & 1.44 & 876 & 729 & 1.19 & 5.20 \\
\hline 31 & 2.6 & $6.50 \mathrm{E}+12$ & 2.12 & $5.75 \mathrm{E}+12$ & 1.65 & 8.0 & 2.10 & 7.3 & 1.98 & 220 & 165 & 2.68 & 5.60 \\
\hline 32 & 2.3 & $2.46 \mathrm{E}+12$ & 1.51 & $1.52 \mathrm{E}+12$ & 1.68 & - & - & - & - & - & - & - & - \\
\hline 33 & 3.6 & $1.51 \mathrm{E}+14$ & 1.45 & $3.02 \mathrm{E}+14$ & 2.14 & 2.4 & 1.83 & 1.9 & 1.62 & 732 & 642 & 1.68 & 4.99 \\
\hline 34 & 2.8 & $1.16 \mathrm{E}+13$ & 3.26 & $1.11 \mathrm{E}+13$ & 2.04 & - & - & 4.9 & 1.78 & - & 246 & - & 3.26 \\
\hline 35 & 2.9 & $1.40 \mathrm{E}+13$ & 1.56 & $1.73 \mathrm{E}+13$ & 2.64 & 5.9 & 1.50 & 4.4 & 1.82 & 299 & 274 & 2.29 & 3.67 \\
\hline 36 & 3.5 & $7.35 \mathrm{E}+13$ & 1.87 & $1.97 \mathrm{E}+14$ & 2.32 & 2.8 & 1.44 & 2.0 & 1.36 & 637 & 602 & 1.24 & 3.93 \\
\hline 37 & 3.3 & $3.59 \mathrm{E}+13$ & 2.45 & $1.20 \mathrm{E}+14$ & 2.61 & 2.4 & 1.59 & 1.7 & 1.19 & 716 & 693 & 0.43 & 1.57 \\
\hline 38 & 3.1 & $1.84 \mathrm{E}+13$ & 1.60 & $6.00 \mathrm{E}+13$ & 1.67 & 2.9 & 1.14 & 1.8 & 1.29 & 597 & 669 & 0.38 & 0.88 \\
\hline 39 & 3.7 & $1.18 \mathrm{E}+14$ & 1.50 & $7.50 \mathrm{E}+14$ & 1.91 & 1.6 & 1.32 & 0.9 & 1.43 & 1111 & 1343 & 0.38 & 1.35 \\
\hline 40 & 4.2 & $8.00 \mathrm{E}+14$ & 1.28 & $2.21 \mathrm{E}+15$ & 1.42 & 2.1 & 1.57 & 1.8 & 1.26 & 832 & 668 & 6.07 & 32.40 \\
\hline 41 & 3.7 & $1.03 \mathrm{E}+14$ & 2.10 & $5.85 \mathrm{E}+14$ & 1.45 & 3.0 & 1.15 & 1.6 & 1.70 & 578 & 740 & 2.33 & 6.32 \\
\hline 42 & 3.1 & $1.85 \mathrm{E}+13$ & 2.32 & $4.83 \mathrm{E}+13$ & 2.94 & 2.7 & 1.77 & 1.7 & 1.73 & 648 & 718 & 0.30 & 0.57 \\
\hline 43 & 2.8 & $1.88 \mathrm{E}+13$ & 1.53 & $7.60 \mathrm{E}+12$ & 2.26 & 3.7 & 1.77 & 3.6 & 1.35 & 471 & 331 & 0.78 & 0.92 \\
\hline 44 & 3.6 & $1.12 \mathrm{E}+14$ & 1.88 & $3.07 \mathrm{E}+14$ & 2.66 & 1.6 & 1.38 & 1.9 & 1.24 & 1069 & 632 & 0.40 & 5.32 \\
\hline 45 & 2.9 & $2.35 \mathrm{E}+13$ & 2.70 & $1.36 \mathrm{E}+13$ & 1.69 & 5.2 & 1.50 & 6.1 & 1.61 & 336 & 198 & 2.71 & 7.72 \\
\hline 46 & 2.7 & $5.35 \mathrm{E}+12$ & 1.81 & $1.87 \mathrm{E}+13$ & 1.16 & 6.4 & 1.48 & 3.9 & 1.54 & 274 & 309 & 1.14 & 2.77 \\
\hline 47 & 3.0 & $1.02 \mathrm{E}+13$ & 3.10 & $5.65 \mathrm{E}+13$ & 2.56 & 5.4 & 1.24 & 4.4 & 1.36 & 325 & 278 & 1.29 & 11.50 \\
\hline 48 & 2.9 & $1.49 \mathrm{E}+13$ & 3.20 & $2.68 \mathrm{E}+13$ & 2.40 & 2.8 & 1.44 & 4.4 & 1.56 & 620 & 277 & 0.27 & 5.54 \\
\hline 49 & 2.9 & $9.40 \mathrm{E}+12$ & 2.01 & $2.97 \mathrm{E}+13$ & 1.19 & 3.9 & 1.65 & 2.0 & 1.17 & 448 & 608 & 0.46 & 0.58 \\
\hline 50 & 4.3 & $1.52 \mathrm{E}+15$ & 1.60 & $3.83 \mathrm{E}+15$ & 2.35 & 1.6 & 1.56 & 1.3 & 1.73 & 1132 & 953 & 4.58 & 19.30 \\
\hline
\end{tabular}

Finally, we have established a well-constrained linear relationship between local magnitude $M_{L}$ and moment magnitude $M_{w}$.

Acknowledgements The reported investigation was financially supported by the Hungarian Scientific Research Fund (No. K68308). We are grateful to Georisk Ltd. for providing the waveform data recorded by the Paks Microseismic Monitoring Network. We also thank two anonymous reviewers for their valuable comments and constructive suggestions. Figures were prepared using the GMT software (Wessel and Smith, 1998). 


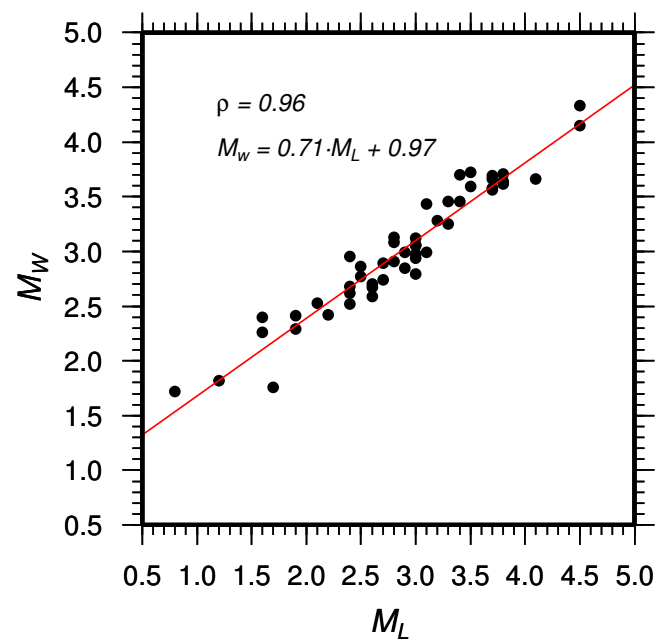

Fig. 10 Relationship between local $\left(M_{L}\right)$ and moment $\left(M_{w}\right)$ magnitudes. The well-constrained best-fitting regression line is also shown. $\rho$ denotes the correlation coefficient.

\section{References}

Abercrombie RE (1995) Earthquake source scaling relationships from - 1 to $5 M_{L}$ using seismograms recorded at 2.5km depth. J. Geophys. Res. 100:24015-24036.

Abercrombie RE, Leary PC (1993) Source parameters of small earthquakes recorded at $2.5 \mathrm{~km}$ depth, Cajon Pass, southern California: implications for earthquake scaling. Geophys. Res. Lett. 20:1511-1514.

Aki K, Richards P (1980) Quantitative Seismology: Theory and Methods. Freeman, San Francisco, California.

Akkar S, Bommer JJ (2007) Empirical prediction equations for peak ground velocity derived from strong-motion records from Europe and the Middle East. Bull. Seism. Soc. Am. 97:511-530.

Allen TI, Gibson G, Brown A, Cull JP (2004) Depth variation of seismic source scaling relation: implications for earthquake hazard in southern Australia. Tectonophysics 390:5-24.

Anderson DL, Ben-Menahem A, Archambeau CB (1965) Attenuation of seismic energy in the upper mantle. J. Geophys. Res. 70:1441-1448.

Archuleta RJ, Cranswick E. Mueller C, Spudich P (1982) Source parameters of the 1980 Mammoth Lakes, California, earthquake sequence. J. Geophys. Res. 87:45954607.

Atkinson GM, Boore DM (2006) Earthquake groundmotion prediction equations for eastern North America. Bull. Seism. Soc. Am. 96:2181-2205.

Babuska V, Plomerová J, Sileny J (1987) Structural model of the subcrustal lithosphere in central Europe. In: Fuchs K, Froidevaux C (eds) Composition, Structure and Evolution of the Lithosphere-Asthenosphere System. AGU Geodyn.
Ser. 16:239-251.

Bada G, Horváth F, Gerner P, Fejes I (1999) Review of the present-day geodynamics of the Pannonian basin: progress and problems. J. Geodynamics 27:501-527.

Badawy A (2000) P-wave spectra of the Füzesgyarmat, eastern Hungary earthquake sequence. J. Seismology 4:4958.

Badawy A, Horváth F, Tóth L (2001) Source parameters and tectonic interpretation of recent earthquakes (1996-1997) in the Pannonian basin. J. Geodynamics 31:87-103.

Bakun WH, Joyner W (1984) The $M_{L}$ scale in Central California. Bull. Seism. Soc. Am. 74:1827-1843.

Bindi D, Spallarossa D, Augliera P, Cattaneo M (2001) Source parameters estimated from the aftershocks of the 1997 Umbria-Marche (Italy) seismic sequence. Bull. Seism. Soc. Am. 91:448-455.

Boatwright J, Fletcher JB, Fumal TE (1991) A general inversion scheme for source, site, and propagation characteristics using multiply recorded sets of moderate-sized eartquakes. Bull. Seism. Soc. Am. 81:1754-1782.

Boore DM, Boatwright J (1984) Average body-wave radiation coefficients. Bull. Seism. Soc. Am. 74:1615-1621.

Boore DM (2003) Simulation of ground motion using the stochastic method. Pure Appl. Geophys. 160:635-676.

Brune JN (1970) Tectonic stress and the spectra of seismic shear waves from earthquakes. J. Geophys. Res. 75:49975009.

Chouet B, Aki K, Tsujiura M (1978) Regional variation of the scaling law of earthquake source spectra. Bull. Seism. Soc. Am. 68:49-79.

Drouet S, Cotton F, Guéguen P (2010) $v_{S 30}, \kappa$, regional attenuation and $M_{w}$ from accelerograms: application to magnitude 3-5 French earthquakes. Geophys. J. Int. 182:880-898.

Dysart PS, Snoke JA, Sacks IS (1988) Source parameters and scaling relations for small earthquakes in the Matsushiro region, southwest Honshu, Japan. Bull. Seism. Soc. Am. 78:571-589.

Fletcher JB (1980) Spectra from high-dynamic range digital recordings of Oroville, California, aftershocks and their source parameters. Bull. Seism. Soc. Am. 70:735-755.

Franceschina G, Kravanja S, Bressan G (2006) Source parameters and scaling relationships in the Friuli-Venezia Giulia (Northeastern Italy) region. Phys. Earth Planet. Inter. $154: 148-167$.

García-García JM, Romacho MD, Jiménez A (2004) Determination of near-surface attenuation, with $\kappa$ parameter, to obtain the seismic moment, stress drop, source dimension and seismic energy for microearthquakes in the Granada Basin (Southern Spain). Phys. Earth Planet. Inter. 141:926.

Gerner P, Bada G, Dövényi P, Müller B, Oncescu MC, Cloetingh S, Horváth F (1999) Recent tectonic stress and 
crustal deformation in and around the Pannonian Basin: data and models. In: Durand B, Jolivet L, Horváth F, Seranne M (Eds) The Mediterranean Basins: Tertiary Extension within the Alpine Orogen. Geological Society, London, Special Publications, Vol. 156, pp. 269-294

Hanks TC, Kanamori H (1979) A moment-magnitude scale. J. Geophys. Res. 84:2348-2350.

Hanks TC, Wyss M (1972) The use of body-wave spectra in the determination of seismic-source parameters. Bull. Seism. Soc. Am. 62:561-589.

Havskov J, Ottemöller L (2010) Routine Data Processing in Earthquake Seismology. Springer, Dordrecht Heidelberg London New York

Havskov J, Peña JA, Ibáñez JM, Ottemöller L, MartínezArévalo C (2003) Magnitude scales for very local earthquakes. Application for Deception Island Volcano (Antarctica). J. Volcanol. Geotherm. Res. 128:115-133.

Horváth F (1993) Towards a mechanical model for the formation of the Pannonian basin. Tectonophysics 226:333357.

Kamae K, Bard P-Y, Irikura K (1998) Prediction of strong ground motion at EURO-SEISTEST site using the empirical Green's function method. J. Seismology 2:193-207.

Kanamori H, Anderson DL (1975) Theoretical basis of some empirical relations in seismology. Bull. Seism. Soc. Am. 65:1073-1095.

Kiszely M (2000) Attenuation of coda-waves in Hungary. Acta Geod. Geoph. Hung. 35:465-473.

Kwiatek G, Plenkers K, Dresen G (2011) Source parameters of picoseismicity recorded at Mponeng deep gold mine, South Africa: Implications for scaling relations. Bull. Seism. Soc. Am. 101:2592-2608.

Oye V, Bungum H, Roth M (2005) Source parameters and scaling relations for mining-related seismicity within the Pyhäsalmi Ore Mine, Finland. Bull. Seism. Soc. Am. 95:1011-1026.

Posgay K, Bodoky T, Hegedús E, Kovácsvölgyi S, Lenkey L, Szafián P, Takács E, Tímár Z, Varga G (1995) Asthenospheric structure beneath a Neogene basin in southeast Hungary. Tectonophysics 252:467-484.

Prieto GA, Shearer PM, Vernon FL, Kilb D (2004) Earthquake source scaling and self-similarity estimation from stacking P and S spectra. J. Geophys. Res. 109:B08310, doi:10.1029/2004JB003084.

Radulian M, Popa M (1996) Scaling of source parameters for Vrancea (Romania) intermediate depth eartquakes. Tectonophysics 261:67-81.

Singh SK, Apsel RJ, Fried J, Brune JN (1982) Spectral attenuation of SH waves along the imperial fault. Bull. Seism. Soc. Am. 72:2003-2016.

Sokolov V, Bonjer KP, Wenzel F, Grecu B, Radulian M (2008) Ground-motion prediction equations for the intermediate depth Vrancea (Romania) earthquakes. Bull.
Earthquake Eng. 6:367-388.

Spottiswoode SM, McGarr A (1975) Source parameters of tremors in a deep-level gold mine. Bull. Seism. Soc. Am. 65:93-112.

Stork AL, Ito H (2004) Source parameter scaling for small earthquakes observed at the western Nagano 800-m-deep borehole, central Japan. Bull. Seism. Soc. Am. 94:17811794.

Süle B (2010) Spectral source parameters for weak local earthquakes in the Pannonian basin. Cent. Eur. J. Geosci. 2:475-480.

Trifunac MD (1972) Stress estimates for the San Fernando, California, eartquake of February 9, 1971: Main event and thirteeen aftershocks. Bull. Seism. Soc. Am. 62:721-750.

Tusa G, Brancato A, Gresta S, Malone SD (2006) Source parameters of microearthquakes at Mount St Helens (USA). Geophys. J. Int. 166:1193-1223.

Tusa G, Gresta S (2008) Frequency-dependent attenuation of $\mathrm{P}$ waves and estimation of earthquake source parameters in southeastern Sicily, Italy. Bull. Seism. Soc. Am. 98:2772-2794.

Wessel P, Smith WHF (1998) New, improved version of generic mapping tools released. EOS, Trans. Am. geophys. Un. 79:579.

Yamada T, Mori JJ, Ide S, Abercrombie RE, Kawakata H, Nakatani M, Iio Y, Ogasawara H (2007) Stress drops and radiated seismic energies of microearthquakes in a South African gold mine. J. Geophys. Res. 112:B03305, doi:10.1029/2006JB004553.

Zobin VM, Havskov J (1995) Source spectral properties of small earthquakes in the northern North Sea. Tectonophysics 248:207-218. 